\title{
Neolithic postscript
}

\author{
PAUL F. WILKINSON
}

\begin{abstract}
In view of the interest generated by Mr Case's article (1969, 176-86) and subsequent discussion (I970, 105-I4), Mr Wilkinson felt that this might be the proper time to introduce the Musk Ox to prehistorians in its new role as a domesticated animal, and make brief reference to some of the other experiments of a large body of useful data which remain largely untapped by archaeologists. $\mathrm{Mr}$ Wilkinson, a research student in the Faculty of Archaeology and Anthropology in the University of Cambridge, also holds the post in the University of Alaska of Associate Director of Research for the Institute of Northern Agricultural Research, which is responsible for the domestication of the musk ox. He wishes to point out that the principal aim of this project is to develop a textile industry based on 'qiviut,' the wool of the musk ox, and thus to better the economic situation of the people of the arctic.
\end{abstract}

Two of the experiments which are worth bringing to the attention of prehistorians are first 'Oomingmak' or the domestication of the musk ox, and secondly the domestication of the moose.

The musk ox has been domesticated by the Institute of Northern Agricultural Research, which maintains herds of tamed and domesticated animals in Alaska, Vermont, Quebec, and Norway (Teal, 1958; 1970a, b.) The nucleus of each herd was wild calves, caught when they were 4-6 months old. At this age they can be manhandled with little difficulty, yet are not too susceptible to injury or to death from shock; most important, they can be tamed easily and permanently. Once mature, these calves were selectively bred to produce offspring with an improved yield of better-quality underwool than their wild counterparts (PLS. XXXI-XXXIII). The underwool, known by the Eskimo term 'qiviut', is collected annually when it is shed and is being used to develop a uniquely arctic textile industry, which, it is hoped, will contribute towards improving the depressed economies of the peoples of the arctic.

With the experiment in the domestication of the moose $I$ am acquainted only through the literature (Knorre, r96r). The domestication of the moose in the USSR on the Pechora-Ilych
State Reservation followed a similar pattern to that of the musk ox and was equally successful. The moose has been domesticated principally as a draught animal, but will be used additionally for milk and meat.

Other domestication experiments are in progress (Huxley, I965; Treus and Kravchenko, 1968) but are inadequately documented with respect to their archaeological significance. All such experiments share one feature: when undertaken properly, they have proved easier and more successful than anticipated. In the light of the above work, four points raised by Case merit further discussion:

(I) '. . . herding cannot have been a simple matter of leaving stock to forage unattended ...' (Case, I969, I77). In fact, there is no reason why such might not sometimes have been the practice. The nature of the relationship between pastoralists and their flocks is determined in part by the seasonal mobility of the species involved and the resource(s) for which it is exploited. The musk ox, for example, does not migrate seasonally, so that close herding is unnecessary. Musk oxen and their herders need come into contact only in spring, when the underwool must be collected and the newly-born calves tamed. Experiments in Vermont demonstrated that tamed musk oxen can be left alone 


\section{ANTIQUITY}

for several years without reverting to 'wild' behavioural patterns. A study of the socialization process in wolves (Woolpy and Ginsburg, 1967) suggested that the age at which animals are tamed might be critical in determining whether or not they remain permanently tame. The Russian herders found that moose could be 'attached' to chosen localities if they learned to associate them with the presence of food and that this bond overrode their urge to migrate. In both instances herders are freed for other subsistence activities for most of the year and the ratio of herders to animals is low. In terms of the model of colonization proposed by Case, advance parties might have been able to leave groups of domesticated animals in Britain until the arrival of the main parties with little danger that these animals would stray or become feral.

Animals raised for meat may also be ranged rather than herded and need not even be tame; for example, many I9th-century range cattle in the United States. On the other hand, animals bred for milk or draught must be on hand more or less constantly and must be tame, requiring stricter control and closer herding. The belief that unattended domesticated animals tend to run with their wild counterparts is well documented for reindeer (Leeds, 1965), but is not universally true. In the Pechora-Ilych State Reservation the reverse occurred, and wild moose were attracted by domesticated (Knorre, 1961). The ranges of wild and domesticated musk oxen do not overlap and the situation is unknown. It is worth remembering that the distribution of wild animals through space is not continuous and that their movements are often predictable, so that wild and domesticated representatives of a single species can be present in the same area without often meeting.

It is of course, difficult to decide which, if any, of these considerations were applicable to the domesticated animals of Neolithic Britain. They must, however, be kept in mind when constructing models of likely human behaviour.

(2) Case considers the servicing of domesticated cows by wild bulls undesirable for three reasons:

(a) it might have interfered with the desired aim of spring calving, (b) the resulting calves might have proved too large for safe delivery,

(c) the offspring of such matings would have been intractable.

Although each point has considerable validity, the situation was probably very flexible. Spring calving may have characterized the wild herbivores of western Europe since it is as desirable for the survival of wild calves as for domesticated-if not indeed more so. The desirability of domesticated-wild crossbreeding depends largely on the breeding strategy of the herdsmen. It was noted above that domesticated musk oxen are being selectively bred to improve the quality and quantity of their underwool. Since this underwool represents their chief non-behavioural adaptation to the arctic winter, it seems safe to assume that it has been selected by nature for the many millennia during which the animal has occupied an arctic habitat. In this case, human and natural selective pressures coincide and the servicing of domesticated cows by wild bulls is not undesirable from this point of view. Tibetan yak herders are also said (Eckvall, pers. comm.) to favour such crosses, which possess better staying power as beasts of burden, and the same is true of the Chukchi reindeer herders (Leeds, 1965 ).

If, as Case suggests, the domesticated cattle of Neolithic Britain were consistently smaller than the wild, the danger of overlarge calves may have been real. Domesticated musk oxen, on the other hand, tend to be larger than wild, partly because they are kept in areas rich in fodder, and partly as a result of the programme of selective breeding. Maintaining animals in such areas is a profitable strategy, for it minimizes the risk that they will stray, improves the quality and quantity of the products they yield, and obviates the need for collecting winter feed. It would be surprising if these advantages were not apparent to prehistoric pastoralists. Since crossbreeding is favoured by some yak and reindeer herders (see above), the danger of large calves cannot be too great in these species. Case assumes, with apparent justification, that inter-breeding between wild and domesticated cattle was prevented in early Neolithic Britain. In view of the preceding comments on the 


\section{NEOLITHIC POSTSCRIPT}

discontinuous nature of the distribution of animals, there may be no need to assume that man actively prevented crossbreeding.

The evidence for the tractability of crossbred calves is conflicting. Selectively bred musk ox calves must be tamed in identical fashion to wild calves, although one of the $197^{\circ}$ calves in Alaska appears to be genetically tame. (It should, however, be emphasized that selective breeding has been practised on a large scale only since 1966 .) Taming wild and domesticated calves is simple, provided that they are less than 6 months old. It is achieved by constant contact between herders and animals for several days after weaning, supplemented by handfeeding for a longer period. At birth, wild musk oxen are as tractable as domesticated and in some respects are easier to tame. In contrast to this, Eckvall reports (pers. comm.) that Tibetan yak herders consider crossbred calves less tractable than pure domesticated calves. The decisive factor is probably whether or not the domesticated calves are genetically tame, but to date there is no means of establishing this from the archaeological record.

(3) Reliance on stored winter fodder may have been less widespread than Case assumes, especially when population densities were low and food resources not overexploited, as would be the situation in newly colonized areas. The labour necessary to collect adequate feed for even a few animals would have been so great that prehistoric man must have made every effort to locate his herds in areas where this was unnecessary. The hay-intake of modern cattle averages at least $2 \mathrm{lb}$. per Ioo lb. ( 0.9 per $45 \mathrm{~kg}$.) body weight per day. Assuming (very conservatively) that a prehistoric bull weighed r,000 lb. (453 kg.) and a cow $700 \mathrm{lb} .\left(3^{1} 7 \mathrm{~kg}\right.$.), and taking the length of winter as $12 \mathrm{I}$ days, it would have been necessary to collect $2,500 \mathrm{lb}$.
(I I34 kg.) of feed per bull, I,700 lb. (770 kg.) per cow, and proportionately lower amounts for calves and yearlings. Such an undertaking would have demanded either a large, surplus labour force or an advanced technology, for neither of which there is convincing evidence in the early British Neolithic.

(4) The most formidable problems are likely to have been associated with transporting animals as large as cattle by sea. Roping and tying adult cattle is a difficult task in many cases and keeping them tied for prolonged periods poses hazards such as death from shock or exhaustion. On the positive side, however, halter-broken animals often show surprising tolerance and blindfolds are very effective in calming frightened animals.

Transporting animals between August and September might have been impracticable, since calves might have been weaned about that time and the bulls were probably rutting from late August until early October. If the collection of winter forage were unnecessary, mid-October to mid-November might have been a good time, and advance parties could have made preparations for the winter. Considering the ease of domesticating animals serious consideration must be given to the possibility that only a few, if any, large domesticated animals were moved and that these were supplemented by capturing indigenous wild stock.

It is hoped that the preceding comments have illustrated the potential value to prehistorians of data derived from current experiments in animal domestication. They are not intended as a critique of Case's thesis and he has performed a valuable and necessary service by emphasizing the need for prehistorians to remember that it is with human beings that they are tealing, not with ciphers.

\section{BIBLIOGRAPHY}

CASE, H. 1969. Neolithic explanations, Antiquity, XLIII, $176-86$.

HUXLEY, E. 1965. Getting a bead on the 'roos, New York Times Magazine, 24 October.

KNORRE, E. P. I961. Results and perspectives of moose domestication, Papers of the PechoraIlych State Reservation, Ix, 5-I77. Translation in Canadian Wildlife Service Library.
LEEDS, A. 1965. In A. Leeds and A. P. Vayda (eds.), Man, culture and animals, 87-128.

RENFrew, C. I 968 . Models in prehistory, Antiquity, XLII, I $32-4$.

TEAL, J. J., JR, 1958. Golden fleece of the arctic, The Atlantic, 201, 76-81.

1970a. Domesticating the wild and woolly musk ox, National Geographic, I 37, 862-79. 


\section{ANTIQUITY}

1970b. Operation musk ox I969, American Scandinavian Review, LVIII, ro-23.

TREUS, v. and D. KRAVCHENKo. 1968. Methods of rearing and economic utilization of eland in the Askaniya-Nova Zoological park, Symp. zool. Soc. London, 21, 395-4II.
TrigGER, в. G. r969. More on models, Antiquity, XLIII, 59-62.

WOOLPY, J. H. and B. E. GINSBURG. 1967. Wolf socialization: a study of temperament in a wild social species, Amer. Zool., viI, 357-63.

\section{Book Chronicle}

We include here books which have been received for review, or books of importance (not received for review) of which we have recently been informed. We welcome information about books, particularly in languages other than English or American, of interest to readers of ANTIQUITY.

The listing of a book in this chronicle does not preclude its review in ANTIQUITY.

Zehn Jahre Archäologische Forschung (1958-r968). Budapest : Archäologisches Institut der Ungarischen Akademie der Wissenschaften, I970. I8I pp., 43 pls., I map.

Détection aérienne de vestiges protohistoriques gallo-romains et médiévaux dans le bassin de la Somme et ses abords. Bulletin No. 7 by Roger Agache. Amiens: Musée de Picardie, r97o. 231 pp., numerous pls. and figs. Frs. 35 .

Metallurgical reports on British and Irish Bronze Age implements and weapons in the Pitt-Rivers Museum by I. M. Allen, D. Britton and H. H. Coghlan. Oxford: University of Oxford, 197o. $283 \mathrm{pp} ., 28 \mathrm{pls.}$, 134 figs. $£^{2.50}$.

Camelot and the vison of Albion by Geoffrey Ashe. London: Heinemann, r97r. 233 pp. f.3.15.

Animal traps and trapping by James A. Bateman. Newton Abbot: David \& Charles, I971. 286 pp., 39 pls., 80 figs. £.3.50.

History on the ground by Maurice Beresford. London: Methuen, I971. 256 pp., 17 pls., 28 figs. $\{3.25$.

Germanen und Kelten bis zum Ausgang der Römerzeit by Helmut Birkhan. Vienna: Hermann Böhlaus, 1970. 636 pp. Austrian schillings 580 .

The ille-de-France: the country around Paris by Marc Bloch, translated by J. E. Anderson. London: Routledge $\mathfrak{F}^{\circ}$ Kegan Paul, I97I. I90 pp., 9 pls., I map. £.2.25.

Athenian building policy from $56 r / 0-405 / 4$ BC by Joh. S. Boersma. Groningen: WoltersNoordhoff, I970. 302 pp., numerous diagrams, 6 separate plans and 5 maps (in folder). Fl. 66,85. $\$ 18.60$.
Indian painters and white patrons by $\mathrm{J}$. J. Brody. Albuquerque: The University of New Mexico Press, I97I. 255 pp., 8 pls. (colour), 92 figs., 2 maps. \$I 5.00.

The Summer Island site. A study of prehistoric cultural ecology and social organization in the Northern Lake Michigan area. Number $r$, by David S. Brose. Cleveland: Case Western Reserve, I970. 80 pp., 5 pls., II figs., I2 tables. fI. 30 .

The world of late antiquity from Marcus Aurelius to Muhammad by Peter Brown. London: Thames and Hudson, I97I. 216 pp., numerous pls. (some in colour). £2.00 cloth; £. .05 paper.

Ancient culture and society: social conflicts in the Roman Republic by P. A. Brunt. London: Chatto $\mathcal{E}^{\circ}$ Windus, 197I. 172 pp., 3 maps, I table. £I.5O.

Search for Sybaris by Orville $H$. Bullitt. London: Dent, I97I. 252 pp., 16 pls., 5 figs. $£ 2.75$. Foreword by Froelich G. Rainey.

The Zimbabwe culture: ruins and reactions by G. Caton Thompson. London: Frank Cass, 1971 . African prehistory No. I. Second edition, first published I93 I. 324 pp., 73 pls., 26 figs. $£ 8.40$.

English place names and their origins by G. J. Copley. Neroton Abbot: David $\mathcal{E}^{\circ}$ Charles, I97I. First published 1968, 188 pp. $£ .75$.

Ancient monuments of Tayside by Herbert Coutts. Dundee: Dundee Museum and Art

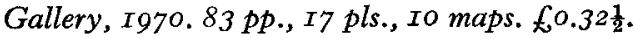

Fishbourne: a Roman palace and its garden by Barry Cunliffe. London: Thames and Hudson, 197I. 228 pp., 93 pls. (7 colour), 40 figs. $£ 4.50$ cloth; £2.ro paper. 


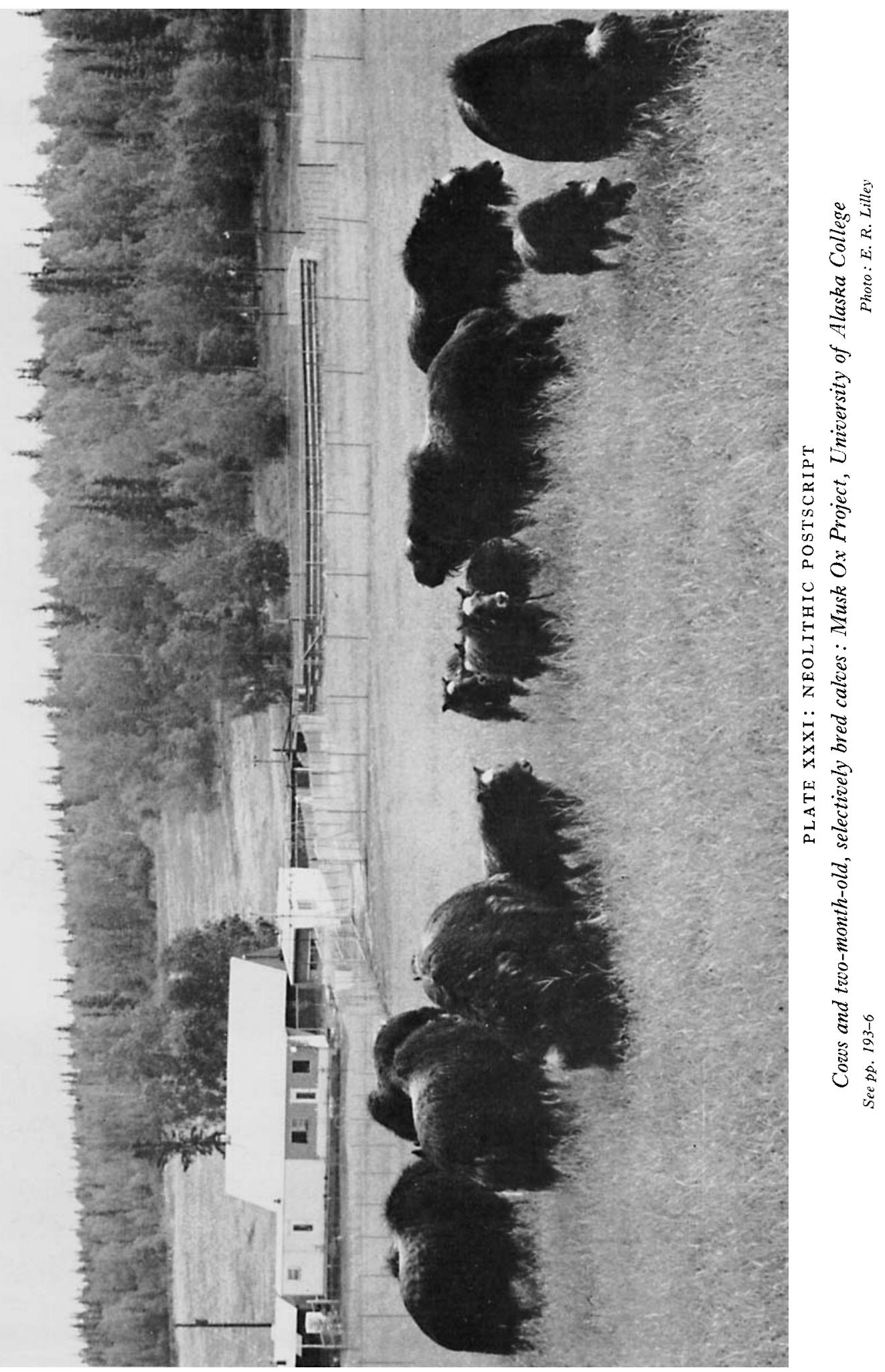



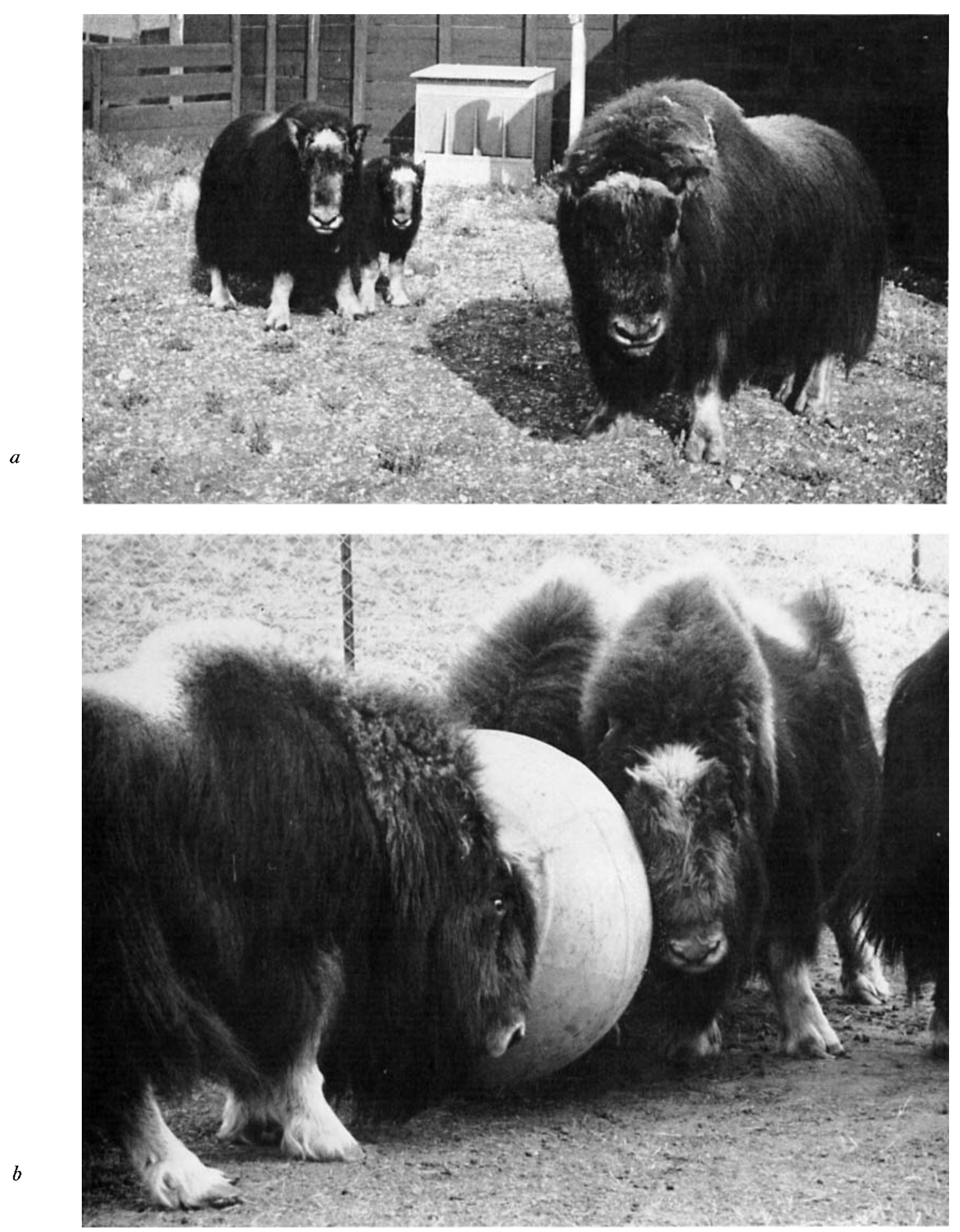

PLATE XXXII: NEOLITHIC POSTSCRIPT

(a) Sire, dam and calf (b) Bull musk oxen playing ball. Musk Ox Project

See pp. 193-6

Photos: F. Bedford, University of Alaska 


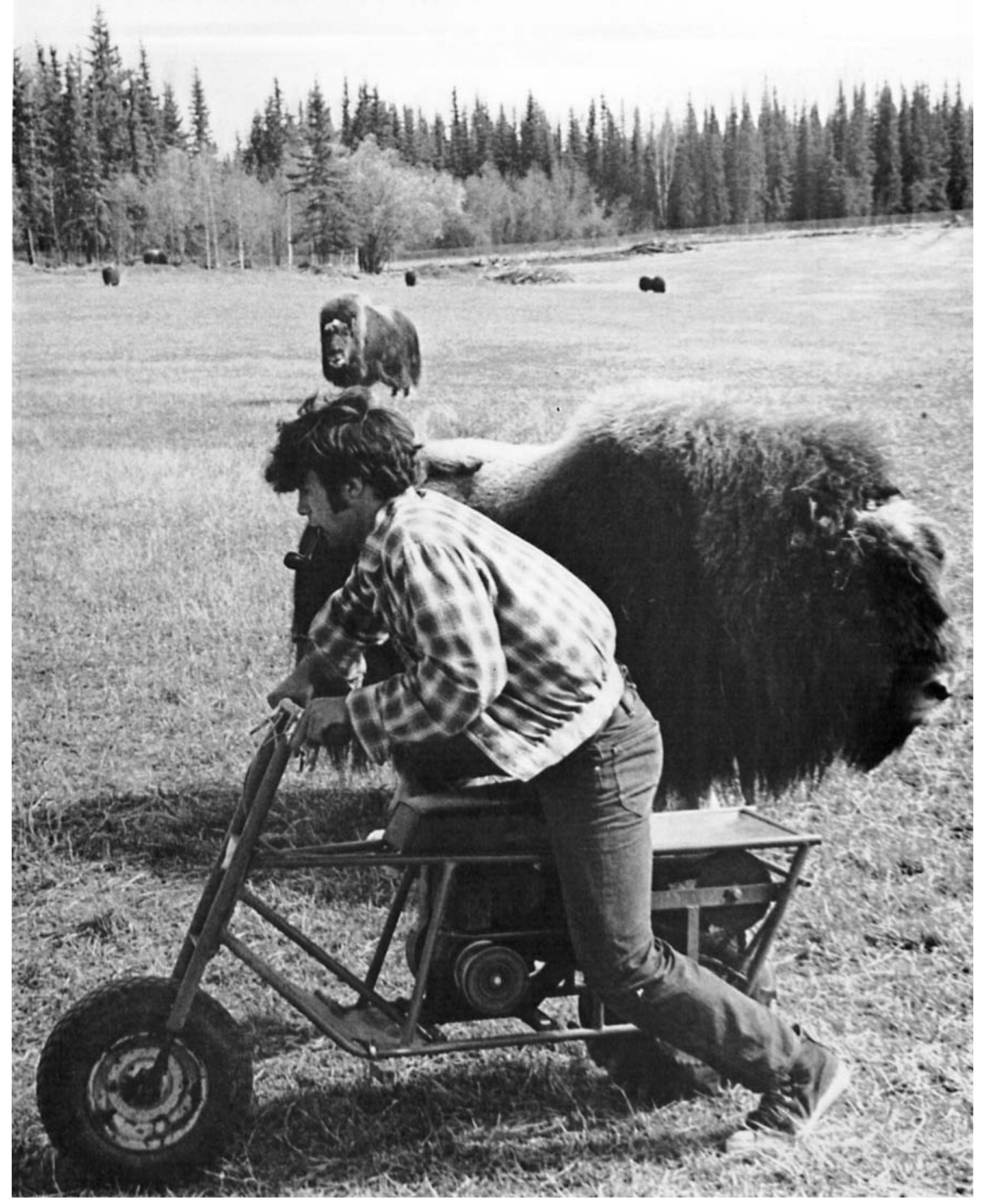

PLATE XXXIII: NEOLITHIC POSTSCRIPT

Herdsman in pasture with mature bulls 